\title{
Patterns of consumption of cyber-pornography amongst women in Mumbai
}

\author{
Pia Sanghvi ${ }^{1}$, Pragya Lodha ${ }^{2}$, Avinash De Sousa ${ }^{3}$ \\ ${ }^{1,2}$ Post graduate student, Department of Psychology, Smt Maniben Nanavati Women's College, Mumbai. \\ ${ }^{3}$ Research Associate, Department of Psychiatry, Lokmanya Tilak Municipal Medical College, Mumbai. \\ Email - pragya6lodha@gmail.com \\ Corresponding author - Ms. Pragya Lodha
}

\begin{abstract}
Introduction: Cyber pornography refers to sexually explicit material on the Internet that is primarily designed to produce sexual arousal in viewers. Research reveals a large number of male consumers for pornography however; recently a growth in the number of female viewership has also been reported by studies. The aim of this research study was to examine the consumption of cyber pornography among women living in the city of Mumbai. The research questions of the study involved exploring the number of women who view cyber pornography along with the association of emotional distress, access efforts and addictive patterns with viewing online pornography.

Methodology: A sample of 150 women between the ages of 18 to 25 years was chosen for the study. The present study utilizes the Cyber Pornography Use Inventory-9 (CPUI-9) as a tool to understand the consumption of pornography under 3 dimensions - perceived compulsivity, access efforts and emotional distress. A Google form of the survey was sent to the participants via email and WhatsApp. The data was analyzed by using statistical tools such as descriptive statistics and graphical representations with respect to the research questions of the study.

Results: Very few (4 out of 150) women were addicted to pornography and an approximate percentage of $41 \%$ did not view pornography online. A highlighting result was that associated to emotional distress among women, as 14.7 percent of women reported feeling ashamed and 8 percent said that they felt sick and depressed after viewing cyber pornography. Future implications and suggestions for future research were discussed.

Conclusion: Results showed that normal obsessions occur to a great extent in the general (non-clinical) population and are mostly overlooked or left unattended. With over 50 participants scoring above the criterion score of 80 (as mentioned), it shows that the OC phenomena is considerably prevalent and can be explored further. The future implications for the study are immense, since such a research has not been undertaken in the Indian context.
\end{abstract}

Key words: pornography, women, cyber-pornography, obsessions, compulsivity.

(Paper received $-29^{\text {th }}$ May 2017, Peer review completed $-28^{\text {th }}$ June 2017, Accepted $-30^{\text {th }}$ June 2017)

\section{INTRODUCTION}

New York Law School professor Nadine Strossen had in 1995 written "Freedom of speech consistently has been the strongest weapon for countering misogynistic discrimination and violence, and freedom of sexually-oriented expression is integrally connected with women's freedom".

The etymology of pornography is traced to its components- graphos (writing or description) and porneia (prostitutes). It means the description of the life, manners and style of prostitutes and their patrons. In the eighteenth century, the city of Pompeii was discovered with its entirety full of erotic art and frescoes, symbols, inscriptions and artifacts that were regarded as 'pornographic' by its excavators. This was when 
the first known use of the word was to describe something similar to pornography was used as understood today. In the modern times, one of the commonly accepted definitions of "pornography" defined it assexually explicit material that is primarily designed to produce sexual arousal in viewers [1].

In India, pornography is seen as an aggravated form of obscenity. Pornography is available in several media forms such as that in print magazines, videotapes and DVDs but it is mainly consumed using the Internet. Pornography that is streamed online, on the Internet is referred to as cyber pornography. Its consumption has been increasing with the increased prevalence of smart phones and the Internet. Despite the accelerated access, public discourse and attitudes on pornography remain muted. As consumers, men and women, both are consumers of pornography, however, the consumption of pornography in women remains restricted due to socially and culturally assumed reasons [2].

Research statistics reports that 38 million users view pornography via mobile devices (smart phones). In a survey conducted of 8,000 girls and women in India, 49\% said they learned about sex from watching porn videos. Almost equivalent to the issue of addiction to substance has been the issue of addiction to pornography. It has been on a continual rise with a cosmopolitan survey reporting crucial data inclusive of $70 \%$ of 18 to 34 year olds use porn once a month, $90 \%$ of therapists see more problems related to porn use and $94 \%$ of therapists have seen a rise in people addicted to porn [3].

It is been found that India has the maximum number of people in the age bracket of young adults and statisticians claim that two thirds of the country's population is below 35 years. It is indicative of the sexually active population, ironically in a country where anything related to sex itself is a taboo. With respect to consumption of pornography, it is always assumed that the larger and only consumers of the same are likely to be men. However, studies reveal that women are also active consumers and the number of female consumers or porn is on an ever increasing high [4].

A new study claims that Indian women are slowly bridging the gap when it comes to watching porn online, with as much as 30 percent of women in India (in 2015) regularly visiting porn websites in the present times. This is a rise by $4 \%$ from the year 2014, where the total number of female porn viewers accounted for $26 \%$ and $6 \%$ higher than the global average of women consumers. There are several statistics of importance with regard to female porn consumers that have been discussed in several articles and research studies. The attitudes towards pornography, preference of pornography and several other data have been compiled with reference to female viewership. What is often discussed is the degree of sexual violence and aggressive sexual behavior is replicated in real life as a consequence of watching aggressive and abusive pornography [5].

What also comes into question is if Indian women are watching excessive porn and incidences of psychiatrists' comments highlighting the danger of porn addiction among women. It has been said that though men have always been considered as the main consumers of porn, a number of recent studies reveal a new trend where rising number of women are not only consumers of online pornography but some of them may have developed an addiction. Psychologists believe that pornography addiction does not discriminate gender [6].

According to data released by leading online pornography network, PornHub claims that Indian women are among the highest consumers of pornography. Interestingly, the data also revealed that Indian women spent an average half a minute longer per visit to a website hosting pornography, as compared to their male counterparts. High tech analytics revealed in a study that the average session time for Indian women visitors was 8 minutes and 31 seconds, while Indian men stayed just a little over 8 minutes. The global average for time spent by women per session is 10 minutes and 10 seconds, as compared to men, whose average session duration was only 9 minutes and 22 seconds [7].

Sarah Cates [8] undertook a research to examine predictors and effects of pornography exposure among women. Results of the data indicated that $72.62 \%$ endorsed sexually explicit material consumption, with $62.93 \%$ reported use within the last 6 months. Correlational analyses revealed a positive relationship between pornography consumption, sexual compulsivity, hypersexuality, and conning and superficial charm. Pornography consumption was not related to sexual interest in women, age, number of sexual partners, child sexual abuse history, impulsivity, lack of perspective taking/empathy and rape myth acceptance. Mediation analysis of the data revealed that precocious sexualization predicted recent consumption and hypersexuality but hypersexuality did not mediate the relationship between recent 
consumption and precocious sexualization. Moderation analysis revealed that neither early exposure nor child sexual abuse predicted hypersexuality and that child sexual abuse did not moderate the effect of hypersexuality and early exposure.

Chitta [9] attempted to study the relationship between exposure to pornography and notions of sexuality in urban India. The researcher used conceptual and relationship content analysis methods to uncover the relationship between the two. The data obtained revealed that exposure to pornography was correlated with sexual practices, high level of sexual awareness and physiology. It was found that consumers of porn seemed to have a greater willingness to experiment with unusual sexual practices. However, exposure to porn did not correlate with unrealistic expectations of partners, level of respect for physical intimacy and diminished degree of respect for the partner's choices and preferences.

A study aimed to examine the relationships between pornography acceptance and use, sexual activity and online sexual compulsivity. These variables were also studied in association with spirituality and religiosity. The sample population consisted of male and female undergraduate and graduate students. Results revealed that $64 \%$ of the men, $56 \%$ of the women hold that viewing pornography is acceptable, while $84 \%$ of the men and $42 \%$ of the women view pornography to some degree. Analysis of data showed associations between high pornography acceptance, high sexual activity (mostly women) high use of pornography and online sexual compulsivity. With respect to religiosity and spirituality, associations between low acceptance and use of pornography and high religiousness and spirituality were found. Recommendations, suggestions for future research and implications of the findings were discussed [10].

Gender differences have been reported when it comes to consumption of pornography. And according to a study, the difference is significant in women than in men after marriage. The study states that women watch more porn after getting married, while the opposite is the case for men. A team of researchers interviewed a hundred married men and women to establish how behavior and attitudes towards sexuality change before and after marriage. Of female participants, 9\% reported viewing pornography before marriage while $28 \%$ said they viewed it after marriage. The reverse trend was noted in married men; with $23 \%$ saying they viewed it before marriage while $14 \%$ viewed it after marriage. The team concluded that the consumption of pornography increases after marriages in females and decreases in males with highly significant difference. They suggest that higher level of sexual desire has already been correlated with greater pornography use [11-12].

Hald [13] conducted a study to investigate gender differences in pornography consumption as well as situational, interpersonal and behavioral characteristics among Danish heterosexual adults. The results of the study revealed significant gender differences on variables related to use and exposure of pornography. It was found that men as compared to women consumed more pornography as measured by frequency and time, used pornography more often when alone and were exposed at a younger age. With reference to preferences it was found that men preferred watching a wide range of hardcore pornography and less softcore pornography than women. In the interpersonal context, women claimed that they used pornography more often with a regular sexual partner whereas men were found to use pornography with their friends (non-sexual partners) or on their own.

In the behavioral context, it was found that men masturbated more and at an earlier age than women. Within the situational context no gender differences were revealed as both genders usual place of use was at home. Key factors in understanding pornography consumption such as gender norms, social acceptability were identified and discussed [14].

In a 2009 study [15] data was obtained through self-administered postal questionnaires. Results revealed that majority of the couples did not use any kind of pornography to enhance their sex lives. However, the results showed that $15 \%$ of the couples, $3 \%$ of female partners and $5 \%$ of male partners had used pornography. The findings disclosed that couples in which only one partner used pornography, problems related to arousal in males and negative self-perception in females was noted. Discriminant function analysis revealed that couples in which one or both partners used pornography a more permissive erotic climate was present as compared to couples that did not use pornography.

Social pressure on women to suppress their sexual desire is proposed to have likely played a part in the surge among female viewers of porn. India also featured among the youngest female consumers of porn, with an average age of 31 years. Only Philippines, with an average age of 30, had younger women 
consuming porn. Indian men, with an average age of 30, were the youngest consumers of porn, the data revealed. Compared to the worldwide average of 24 percent female porn viewers - an increase of one percent over the previous year, the Philippines and Brazil took the lead with 35 percent female viewers. India and Argentina came in a close second with 30 percent female porn viewers. Women have been consuming and enjoying porn for a long time and are not just a fringe minority. One in three adults browsing Internet porn sites are women, according to Nielsen ratings [16].

The current research study aims to study consumption of cyber pornography among women living in the city of Mumbai. We aim to target questions like - what is the percentage of women that use cyber pornography, whether women experience emotional distress after viewing online pornography, whether women make efforts to access online pornography and whether women show addictive patterns with relation to online pornography use.

\section{MATERIALS AND METHODS}

A sample size of 150 women living in the city of Mumbai was part of the research study. The age range of the participants was 18 to 25 years. The sampling techniques that were used were convenience and snowball sampling (non-probability sampling). The control group was between 18 to 24 years, female gender and having a proficiency in English.

\section{Procedure}

The researchers created a Google form of the survey. They then approached women between the ages of 18 to 25 years living in the city of Mumbai. The survey was sent to the participants via email and Whats App. Confidentiality of the data was maintained. The data was analyzed using statistical tools such as descriptive statistics and graphical representations with respect to the research questions of the study.

\section{Operational Definitions for the study}

Cyber pornography refers to sexually explicit material on the Internet that is primarily designed to produce sexual arousal in viewers.

Research Design: The research design of this study is a survey design using an online inventory.

\section{Research Instrument}

Cyber Pornography Use Inventory - 9 (CPUI - 9) is a scale developed by Grubbs and others [17]. It is a 9item scale that measures Internet pornography use. The scale is a modified version of the original Cyber Pornography Use Inventory (CPUI) that was developed in 2010 [18]. The subscales of the scale are perceived compulsivity, access efforts and emotional distress. The responses of the scale can be in Likert or True/False formats. The researchers converted the scale into a True or False format with an additional response option of 'I don't view online pornography' for items $2,3,7,8,9$. The reliability of each subscale is 0.80 or greater.

\section{RESULTS \& DISCUSSION}

The present study is Mumbai based, conducted on 150 females between the ages of 18-25 years. The Cyber Pornography Use Inventory 9 (CPUI-9) was used to gather information with regard to the cyber pornography consumption in the target population. The median age of females in the study is 21 years.

Results indicate that $97.3 \%(146 / 150)$ respondents are not addicted to Internet or cyber pornography and subsequently only a feeble share of $2.7 \%$ is addicted to it (the same is represented in Graph 1 ). With an approximate of $41 \%$ respondents (62 respondents) not viewing pornography online, of the remaining respondents ( 88 respondents) and those who are addicted to it, $4.7 \%$ females feel drawn to pornography even when they don't want to use or view online pornography and $5.3 \%$ of females feel unable to put an 
end to their use of cyber pornography. The results of the present study are indicative of the current trends that claim cyber pornography addiction is rising in women and overall, in the population of ages 18-30 years.

Carrying forward a further finding that is indicated with regard to addiction to pornography in women, is that $8.7 \%$ of the female respondents arranged a schedule or circumstance for themselves that enabled them to be alone and so that they could watch pornography. A share of $3.3 \%$ of the surveyed respondents said that they had kept aside priorities in order to satiate themselves with cyber pornography. However, a small percentage of $1.3 \%$ women denied going out for social outings with friends and family in order to satisfy their need of watching pornography. These trends demystify the misconception that women do not view pornography or are barely exposed to it. Though less, women do prefer watching pornography that caters to their pleasure.

The possibility of lesser number of female viewership is also attributable to the lesser incidences of revelation among women. Studies have shown that a larger portion which goes up to as high as 70 percent, women refrain from disclosing their cyber pornography consumption. A comparatively less consumption of pornography in women is argued by feminists who say that there is a lot of violence against women in the sense that they are treated as less than equal in some. Women seem like an unintelligent participant watching the film, which is not a pleasurable activity for them. Though there is alternative erotica (pornographic content with relational value) to address some of these issues, it is not sufficient. Only a handful of women claim that there is erotica, which is female friendly, feminist, or alternative porn [1920].

There have been captivating results indicating emotional distress, alternatively, various negative emotions attached with viewing pornography in females. Feelings of depression, being ashamed and feeling sick are the three dimensions covered in CPUI-9 and all the three have been found to be associated with watching cyber pornography in women. Results show that $8 \%$ of women respondents feel depressed and an equivalent $8 \%$ feel sick after viewing pornography. As many as $14.7 \%$ respondents feel ashamed (represented in Graph 4) after viewing online pornography. These findings are a confirmation to the attached stigma about viewing pornography and especially so in female consumers. With the traditional household responsibilities attached and women represented with inferior sexuality and suppressed expression of sexual needs, the expressed negativity of emotions has a huge cultural and social factor to them.

Nevertheless, findings do stipulate consumption of cyber pornography in women. With other sociodemographic factors not taken into consideration, the indication of the category of women as consumers and those addicted to pornography are beyond the scope of this study. The reasons for consumption and addiction of pornography in Indian women (Mumbai based, with reference to this study) are hard to confirm with the constricted studies and research done in this field [21].

In alliance with the present study, research does confirm the expansion in consumption of pornography in not just men but also in women. However, a greater understanding is required to absorb what factors accelerate consumption rates and what are the reasons that consumption of pornography in women is greater after marriage. Further studies and research interventions are required in order to closely understand the patterns of consumptions of cyber pornographic content in women and how it is addictive and impacting the relationships in real life [22].

\section{Limitations}

1. The existing research and literature in the area of pornography use among women is limited.

2. The study involved administering a self-report survey, which could have lead to participants giving socially desirable responses. 


\title{
Future Implications
}

1. Research with a larger sample size can be conducted.

2. Research in various areas such as knowledge of, preferences, types, addiction and attitudes towards pornography can be explored.

3. A comparative study between males and females with relation to cyber pornography can be done.

\section{REFERENCES}

1. Langman L. Punk, porn and resistance: Carnivalization and the body in popular culture. Curr Sociol 2008;56(4):657-77.

2. Math SB, Viswanath B, Maroky AS, Kumar NC, Cherian AV, Nirmala MC. Sexual crime in India: Is it influenced by pornography?. Indian J Psychol Med 2014;36(2):147-52.

3. Kamalipour YR, Rampal KR, editors. Media, sex, violence, and drugs in the global village. Rowman \& Littlefield; 2001.

4. Shah N. Subject to technology: internet pornography, cyber- terrorism and the Indian state 1. Inter- Asia Cultural Stud 2007;8(3):349-66.

5. Verma A. Cyber pornography in India and its implication on cyber cafe operators. Comp Law Security Rev 2012;28(1):69-76.

6. Gupta C. Sexuality, obscenity, community: Women, Muslims, and the Hindu public in colonial India. Orient Blackswan; 2005.

7. Doran K, Price J. Pornography and marriage. J Fam Economic Issues 2014;35(4):489-98.

8. Cates SA. To each her own: Examining predictors and effects of pornography exposure among women. Palo Alto University; 2015.

9. Ciclitira K. Pornography, women and feminism: Between pleasure and politics. Sexualities 2004;7(3):281301.

10. Smith C. One for the girls!: the pleasures and practices of reading women's porn. Intellect Books; 2007.

11. Hald GM. Gender differences in pornography consumption among young heterosexual Danish adults. Arch Sexual Behav 2006;35(5):577-85.

12. Weiser EB. Gender differences in Internet use patterns and Internet application preferences: A two-sample comparison. Cyberpsychol Behav 2000;3(2):167-78.

13. Hald GM, Malamuth NM, Yuen C. Pornography and attitudes supporting violence against women: Revisiting the relationship in non experimental studies. Aggress Behav 2010;36(1):14-20.

14. Short MB, Black L, Smith AH, Wetterneck CT, Wells DE. A review of Internet pornography use research: Methodology and content from the past 10 years. Cyberpsychol Behav Soc Network 2012;15(1):13-23.

15. Kingston DA, Malamuth NM, Fedoroff P, Marshall WL. The importance of individual differences in pornography use: Theoretical perspectives and implications for treating sexual offenders. J Sex Res 2009;46(2-3):216-32.

16. Zitzman ST, Butler MH. Wives' experience of husbands' pornography use and concomitant deception as an attachment threat in the adult pair-bond relationship. Sex Addict Compuls 2009;16(3):210-40.

17. Grubbs JB, Exline JJ, Pargament KI, Hook JN, Carlisle RD. Transgression as addiction: Religiosity and moral disapproval as predictors of perceived addiction to pornography. Arch Sexual Behav 2015;44(1):12536.

18. Grubbs JB, Volk F, Exline JJ, Pargament KI. Internet pornography use: Perceived addiction, psychological distress, and the validation of a brief measure. J Sex Marital Ther 2015;41(1):83-106.

19. O'Reilly S, Knox D, Zusman ME. College student attitudes toward pornography use. College Stud J 2007;41(2):402-7.

20. Attwood F. What do people do with porn? Qualitative research into the comsumption, use, and experience of pornography and other sexually explicit media. Sexuality Culture 2005;9(2):65-86.

21. Tylka TL, Kroon Van Diest AM. You looking at her "hot" body may not be "cool" for me: Integrating male partners' pornography use into objectification theory for women. Psychol Wom Quart 2015;39(1):67-84.

22. Sinković M, Štulhofer A, Božić J. Revisiting the association between pornography use and risky sexual behaviors: The role of early exposure to pornography and sexual sensation seeking. J Sex Res 2013;50(7):633-41.

\author{
$* * * * * * * * * * * * * * * * * * * * * * * *$ \\ Acknowledgements - Nil; Source of Funding - Nil; Conflict of Interest - Nil
}

